\title{
PENERAPAN PENDEKATAN PRAGMATIS: BENTUK MENGIKUTI FUNGSI DALAM PERANCANGAN ARSITEKTUR INDUSTRI YANG EKOLOGIS
}

\author{
Christina Ferlenthya Puwardii ${ }^{11}$, Priscilla Epifania Ariaji ${ }^{2)}$
}

\author{
1)Program Studi S1 Arsitektur, Fakultas Teknik, Universitas Tarumanagara, ctinafp@gmail.com \\ 2) Program Studi S1 Arsitektur, Fakultas Teknik, Universitas Tarumanagara, priscillae@ft.untar.ac.id
}

\begin{abstract}
Abstrak
Salah satu cara mengatasi permasalahan sampah plastik adalah dengan kesadaran ekologis memanfaatkan perkembangan teknologi untuk mengolah sampah tersebut sebelum dibuang. Pengolahan tersebut dapat dilakukan dengan mendaur ulang kembali sampah plastik yang masih baik untuk digunakan kembali sebagai bahan baku produksi atau menggunakan metode gasifikasi plasma untuk mengubah sampah plastik yang sudah tidak baik menjadi energi listrik. Disertai dengan ulat lilin sebagai representasi alam sebagai pengurai, metode-metode pengolahan ini tentunya membutuhkan suatu bangunan yang memfasilitasi berjalannya proses, dan bangunan itu biasa disebut sebagai arsitektur industri. Arsitektur industri sebaiknya ramah lingkungan dan bertanggung jawab dalam setiap keputusan yang diambil, baik dalam perencanaan, pembangunan, hingga perawatan. Prinsip utama ini dianut oleh dalam proyek Khanah Kufu: Fasilitas Pengolahan Sampah Plastik di Bantar Gebang. Salah satu pendekatan yang dapat digunakan untuk perancangan arsitektur industri fasilitas pengolahan sampah plastik ini adalah pendekatan pragmatis dengan metode bentuk mengikuti fungsi. Keberhasilan perancangan arsitektur dengan metode ini dapat dicapai melalui pertimbangan perancangan berikut: (1) kebutuhan volume ruang; (2) hubungan antar ruang ; (3) aksesibilitas dan sirkulasi. Diharapkan dengan menggunakan metode ini, hasil perancangan arsitektur industri pengolah sampah plastik dapat mencapai tujuannya untuk menghentikan permasalahan sampah plastik tanpa menghasilkan emisi karbon serta sampah yang baru, bahkan saat bangunan sudah tidak lagi digunakan dan dihancurkan.
\end{abstract}

Kata kunci: arsitektur industri; daur ulang, gasifikasi, dan penguraian; fungsional; metode bentuk mengikuti fungsi; pendekatan pragmatis

\begin{abstract}
One way to overcome plastic waste is to take advantage of technological developments, without ignoring ecological awareness, to process waste before disposal. The process can be done by recycling plastic waste as raw material for production and using plasma gasification to convert recycling leftovers into electrical energy. Along with the usage of waxworm as decomposers, these methods require a building that accomodates the process, and the building is commonly referred as industrial architecture. Eco-industrial architecture should be able to take responsible decisions in every stage of its existence (planning, construction, maintenance, demolition). This main principle is embraced by the Khanah Kufu: Plastic Waste Processing Facility in Bantar Gebang. Pragmatic approach can be used to design this plastic waste processing facility with form following its function. The success of designing eco-industrial architecture can be achieved through the following design considerations: (1) space and volume requirements; (2) space relations; (3) accessibikity and circulation. It is expected that by using this method, design results are able to achieve its goal to overcome the problem of plastic waste without producing new emissions and waste, even when the building is no longer used.
\end{abstract}

Keywords: Eco-industrial architecture; form follow function; functional; pragmatic approach; recycle, gasification, and decomposition

\section{PENDAHULUAN Latar Belakang}

Salah satu permasalahan yang sudah lama berlangsung dan sangat sulit diatasi adalah sampah, 
terutama jenis plastik. Sampah ini menggunung di tempat pembuangan sampah akhir hingga ke memenuhi lautan. Menurut laman Sistem Informasi Pengelolaan Sampah Nasional (diakses pada 2 Februari 2021), sekitar 175.000 ton sampah dihasilkan di Indonesia setiap harinya dan 15\% dari sampah-sampah tersebut adalah sampah plastik. Sumartiningtyas (2020) juga menyatakan bahwa tidak sedikit masyarakat yang sudah menyadari permasalahan ini, tetapi produksi sampah plastik terus bertambah akibat kebutuhan akan material plastik yang tetap meningkat. Berbagai solusi sudah diutarakan oleh peneliti dari berbagai penjuru dunia, tetapi yang saat ini digunakan hanyalah pembakaran sampah dikarenakan pengoperasiannya yang paling mudah. Walau demikian, pembakaran bukanlah solusi terbaik akibat emisi gas beracun dan abu pembakaran yang diproduksinya.

Solusi permasalahan sampah plastik yang ramah lingkungan adalah daur ulang dan gasifikasi plasma. Menurut Styana (2019), kedua proses ini tidak menghasilkan emisi berupa gas beracun dan tidak menghasilkan sisa pembakaran berupa abu. Selain itu, hasil pemrosesan dengan kedua metode ini berupa energi listrik dan bahan baku produksi plastik dapat dimanfaatkan manusia dalam kehidupan sehari-hari. Walaupun demikian, kedua proses ini tetap membutuhkan energi untuk bekerja dan diharapkan energi yang digunakan tidak berasal dari pembakaran batu bara. Maka dari itu bangunan menggunakan hasil gasifikasi plasma sebagai sumber energi untuk menjalankan mesinnya, sedangkan untuk memulai gasifikasi plasma menggunakan energi dari panel surya. Kemudian peternakan ulat lilin juga dimanfaatkan untuk meningkatkan kesadaran ekologis pada masyarakat.

Arsitektur industri yang mewadahi proses pengolahan sampah plastik perlu dirancang agar tidak menimbulkan efek samping pada lingkungan. Pendekatan perancangan dan metode yang digunakan harus sesuai agar dapat memaksimalkan nilai fungsional, efisiensi, dan keberlanjutan dalam bangunan. Maka pendekatan yang digunakan pada perancangan fasilitas pengolahan sampah plastik ini adalah pendekatan pragmatis dengan metode perancangan bentuk mengikuti fungsi.

\section{Rumusan Permasalahan}

a. Sampah plastik di Indonesia masih diolah tanpa kesadaran ekologis dan menyebabkan pengolahan menjadi tidak ramah lingkungan.

b. Bangunan industri yang digunakan untuk mewadahi kegiatan pengolahan sampah bersifat fungsional dan efisien tetapi belum ramah terhadap lingkungan sekitar.

c. Pendekatan pragmatis dan metode perancangan bentuk mengikuti fungsi yang diterapkan pada arsitektur industri untuk menciptakan bangunan yang fungsional, efisien, dan ramah lingkungan.

\section{Tujuan}

Penulisan ini bertujuan untuk membongkar secara detail proses penerapan pendekatan pragmatis dan metode perancangan bentuk mengikuti fungsi dalam proyek dengan judul Khanah Kufu: Fasilitas Pengolahan Sampah Plastik di Bantar Gebang untuk menghasilkan perencanaan yang fungsional, efisien, dan ramah lingkungan. Diharapkan penulisan ini dapat memberikan pengertian yang lebih mendalam kepada pembaca mengenai penerapan pendekatan pragmatis dengan metode bentuk mengikuti fungsi.

\section{KAJIAN LITERATUR}

\section{Arsitektur Industri yang Melampaui Ekologi}

Menurut Manvi (2017), bangunan industri selama ini dikenal sebagai salah satu objek yang berandil besar dalam mencemari lingkungan, baik itu pada air, udara, maupun suara. Hal ini terbukti dari data-data bahwa biasanya lingkungan di daerah industri lebih panas, pengap, dan 
tercemar. Tetapi muncul pergerakan baru eco-industrial yang mempromosikan bangunan industri ramah lingkungan. Menurut Conticelli (2014), kriteria perancangan arsitektur industrial ekologis adalah sebagai berikut.

a. Pemulihan sumber daya, pencegahan polusi, dan produksi yang lebih bersih;

b. Integrasi ke dalam ekosistem alam;

c. Desain berkelanjutan;

d. Penilaian siklus hidup;

e. Sistem manajemen lingkungan;

f. Dekonstruksi dan demanufaktur;

g. Inovasi teknologi dan perbaikan lingkungan yang berkelanjutan;

h. Partisipasi dan kolaborasi publik.

Sedangkan untuk mencapai arsitektur yang melampaui ekologi, Sutanto (2020) menyebutkan beberapa parameter yang harus masuk ke dalam perancangan, seperti: energi dan emisi, adaptasi, resiliensi, digital berkelanjutan, teknologi baru, dan kontekstual.

\section{Metode Bentuk mengikuti Fungsi pada Arsitektur}

Metode perancangan Bentuk Mengikuti Fungsi (form follows function) yang pertama kali diperkenalkan oleh Louis Sullivan adalah salah satu metode perancangan yang bersifat pragmatis. Metode ini hanya berfokus pada sifat fungsional pada suatu bangunan. Setiap perubahan bentuk dan setiap ornamen dekoratif yang terpasang harus memiliki alasan fungsional. Menurut Hwang (2020), ciri-ciri utama pada metode bentuk mengikuti fungsi adalah sebagai berikut.

a. Ruang yang dirancang sesuai dengan fungsinya.

b. Strukturnya yang hadir secara jujur dan tidak perlu dibungkus dengan bentukan massa atau ornamen.

c. Penyederhanaan bangunan sehingga ornamen-ornamen yang hanya berfungsi sebagai estetika tidak diperlukan.

Kemudian penyesuaian fungsi pada metode ini dengan desain industri didasari dengan kebutuhan ruang (volume ruang), akses dan sirkulasi, serta kebutuhan-kebutuhan fungsional lainnya.

Tabel 1. Metode Bentuk Mengikuti Desain (form follows function)

\begin{tabular}{cll}
\hline \multicolumn{1}{c}{ Hasil dari metode } & \multicolumn{1}{c}{ Fokus Desain } & \multicolumn{1}{c}{ Faktor Pendukung } \\
\hline \multirow{2}{*}{ Bentuk bangunan } & Alur aktivitas dan sirkulasi & Material bangunan \\
\cline { 2 - 3 } & Kebutuhan ruang & Struktur \\
\cline { 2 - 3 } & Kebutuhan fungsional & \\
\hline
\end{tabular}

Sumber: Penulis, 2021

\section{METODE}

Jenis Penelitian yang dilakukan adalah jenis deskriptif-kualitatif. Menurut Lexy (2011), deskriptif kualitatif menggambarkan dan menginterpretasikan data-data yang terkumpul dengan memberikan perhatian dan mendokumentasikan sebanyak mungkin aspek situasi yang diteliti sehingga memperoleh gambaran secara umum dan menyeluruh tentang keadaan sebenarnya.

\section{Metode Pengumpulan Data}

Pengumpulan data dilakukan dengan observasi dan studi kasus/dokumen. Dalam metode observasi, pengumpulan data dilakukan dengan mengamati permasalahan serta potensi pemecahan masalah secara virtual melalui berbagai video dokumenter. Sedangkan dalam metode studi kasus/dokumen, dilakukan pencarian beberapa dokumen yang menjelaskan 
permasalahan dan potensi serta pencarian studi kasus yang dapat terhubung dengan kebutuhan proyek, seperti standar kebutuhan ruang, kapasitas, peletakan, dan strategi desain yang kemudian akan diolah kembali.

\section{Metode Kompilasi}

Data-data yang telah terkumpul dari metode sebelumnya kemudian dikompilasi untuk dianalisis dan kemudian menghasilkan suatu strtegi perancangan yang siap untuk diaplikasikan dalam perancangan.

\section{Metode Perancangan}

Perancangan proyek pengolahan sampah plastik menggunakan metode pragmatis dengan prinsip bentuk mengikuti fungsi untuk menghasilkan proyek yang fungsional. Desain disesuaikan dengan langgam industri ekologis yang mengedepankan pandangan ekologis ramah lingkungan dan bertanggung jawab dalam setiap pengambilan keputusan. Dalam hal ini, langgam perwujudan prinsip dan langgam berupa bentuk massa yang simetris, penggunaan material yang ramah lingkungan (dapat didaur ulang, digunakan kembali, atau merupakan hasil produk daur ulang)

\section{DISKUSI DAN HASIL}

Proyek Khanah Kufu memfasilitasi pengolahan sampah plastik yang datang dari Jakarta ke TPST Bantar Gebang. Tapak Khanah Kufu terletak di Jl. Raya Narogong, Kec. Bantar Gebang, Bekasi. Perancangan dimulai dengan penentuan tujuan perancangan. Pada proyek ini, tujuan perancangan adalah membuat sebuah fasilitas pengolahan sampah plastik yang mampu mengakomodasi pemilahan sampah plastik untuk didaur ulang, gasifikasi plasma terhadap plastik yang tercampur, kualitas tidak tinggi, dan penguraian sisa sampah plastik yang tidak didaur ulang.

\section{Metode Perancangan Bentuk Mengikuti Fungsi (Form Follows Function)}

Perancangan arsitektur dengan metode bentuk mengikuti fungsi (form follows function) perlu mengetahui terlebih dahulu detail fungsi yang akan dirancang berupa aktivitas dalam bangunan, alur aktivitas, program ruang, kebutuhan luas ruang, kebutuhan ketinggian, hubungan antar ruang, dan kebutuhan-kebutuhan fungsional lainnya yang memberi pengaruh pada massa bangunan.

Pengguna pada proyek terbagi menjadi pengguna tetap dan pengguna tidak tetap. Pengguna tetap, yang berpartisipasi dalam berjalannya proyek, adalah pekerja kantor, pegawai komersial, pekerja masinis, teknis, peternak ulat lilin, dan peneliti. Sedangkan pengguna tidak tetap, yang datang untuk mencapai kebutuhannya kemudian pergi, adalah pengunjung, masyarakat sekitar yang mengumpulkan sampah, dan pengangkut sampah. Berikut adalah tabel perencanaan aktivitas pada proyek. 


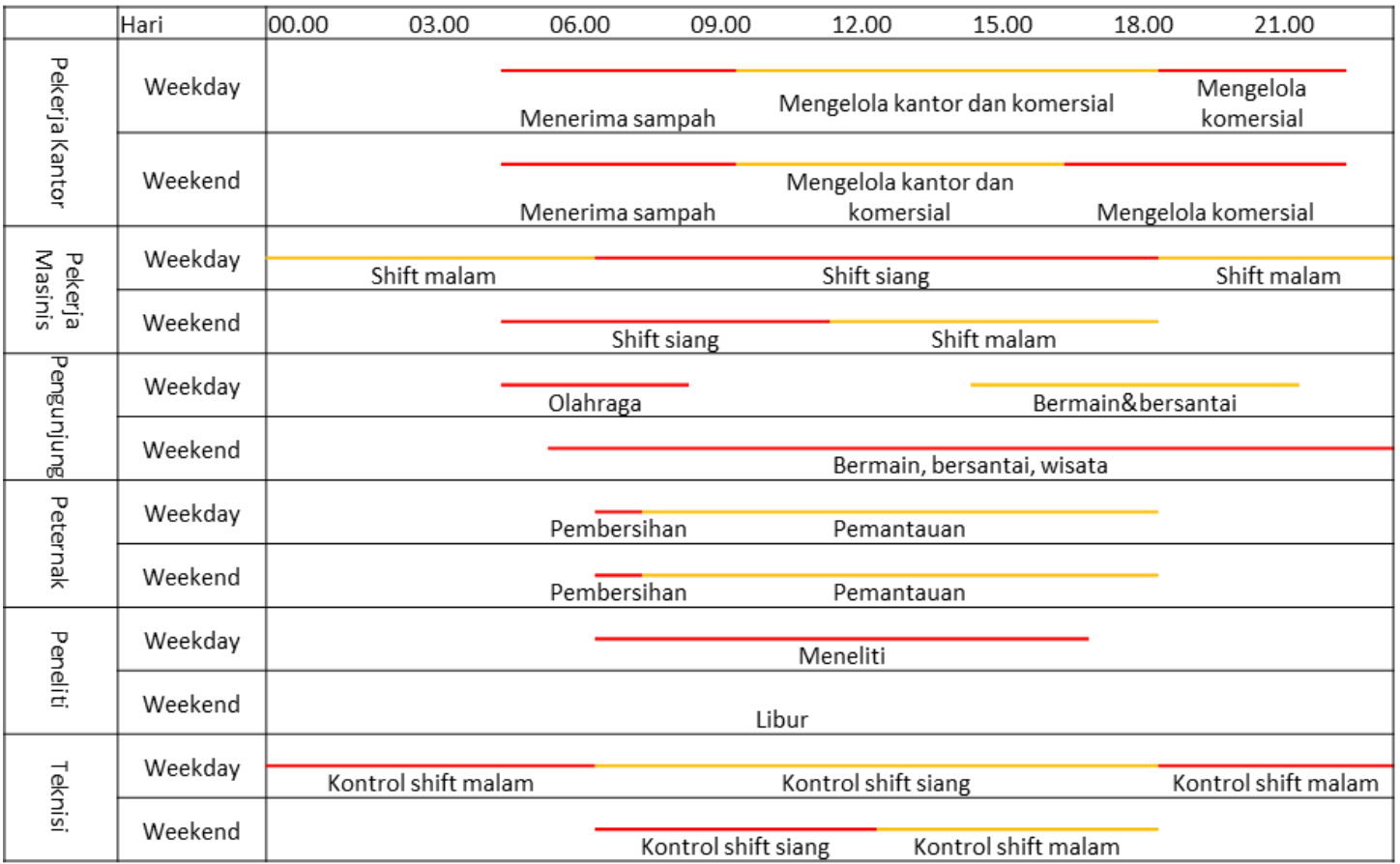

Gambar 1. Aktivitas pada Proyek

Sumber: Penulis, 2021

Alur pengolahan sampah pada proyek yang merupakan aktivitas utama pada proyek adalah sebagai berikut.
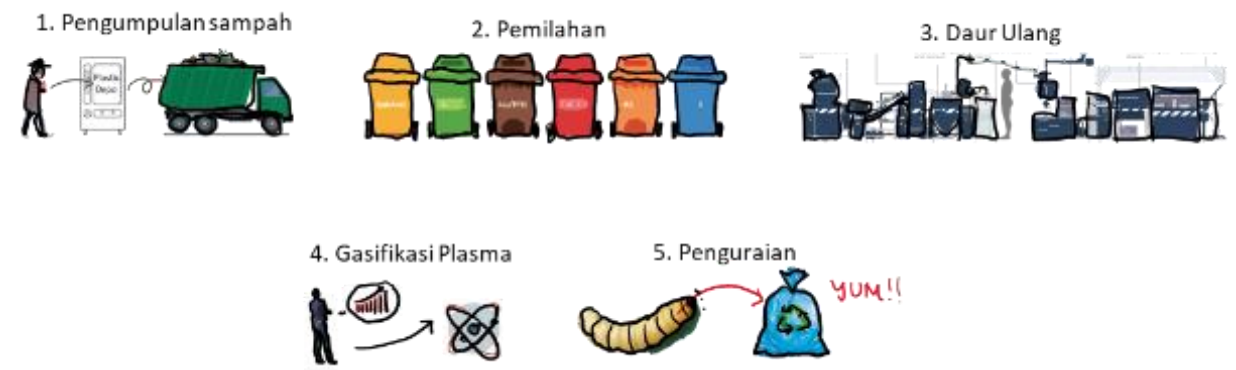

Gambar 2. Alur Aktivitas Sumber: Penulis, 2021

Kebutuhan ruang disesuaikan dengan perkiraan jumlah sampah plastik yang akan diterima proyek, besaran mesin, dan kebutuhan kapasitas ruang. Berikut adalah data programatik ruang pada proyek.

Tabel 2. Program Ruang

\begin{tabular}{lcc}
\hline \multicolumn{1}{c}{ Jenis Kebutuhan (Program) } & Persentase dari Luas Tapak & Luas (m2) \\
\hline Ruang Komersial & $5 \%$ & 1450 \\
\hline Kantor Pengelola & $5 \%$ & 1450 \\
\hline Daur Ulang & $10 \%$ & 2900 \\
\hline GasifikasI Plasma & $10 \&$ & 2900 \\
\hline Peternakan Ulat Lilin & $2,5 \%$ & 725 \\
\hline Rekreasi Masyarakat & $42,5 \%$ & 12325 \\
\hline Servis (Akses dan Parkir) & $25 \%$ & 7250 \\
\hline Total & $100 \%$ & 29000 \\
\hline
\end{tabular}

Sumber: Penulis, 2021 
Berikut adalah hubungan antar program pada proyek.

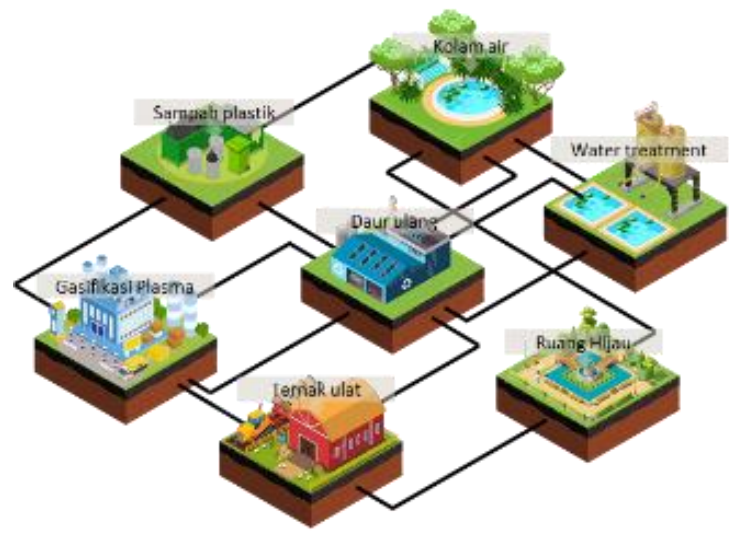

Gambar 3. Hubungan antar Ruang Sumber: Penulis, 2021

Kebutuhan fungsional tambahan pada bangunan adalah sistem pengumpul air hujan yang akan digunakan untuk pengairan dalam proyek, kanopi, dan utilitas bangunan.

\section{Strategi Desain dan Penerapannya}

Pertimbangan-pertimbangan diatas menghasilkan beberapa tahapan strategi desain seperti yang disebutkan berikut ini.

1. Pengaturan peletakan ruang berdasarkan besaran dan hubungan ruang Program pada bangunan divisualisasikan sebagai ruang persegi untuk mencapai efisiensi ruang. Ruang-ruang persegi yang diberi ketinggian kemudian disusun berdasarkan hubungan antar ruang yang sudah direncanakan pada awal proses perencanaan. Tidak lupa peletakan massa pada tapak harus sesuai dengan arus sirkulasi kendaraan di luar tapak agar tidak mengakibatkan kebingungan dalam menentukan sirkulasi dalam bangunan. Fungsi komersial diletakkan dekat dengan muka tapak dan fungsi pengolahan sampah plastik diletakkan lebih mundur dari fungsi komersial. Untuk fungsi rekreasi, dibuat ruang terbuka hijau sehingga tidak banyak mempengaruhi bentukan massa dari proyek.

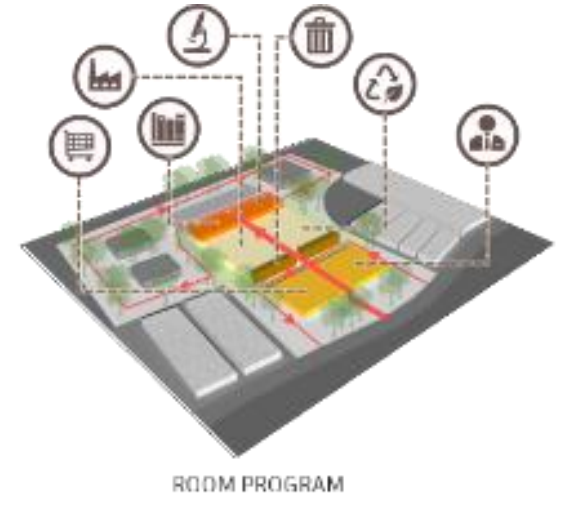

Gambar 4. Implementasi Program dan Hubungan Ruang pada Massa Sumber: Penulis, 2021

2. Penentuan sirkulasi dan akses pada proyek berdasarkan aktivitas Alur sirkulasi pada proyek terbagi menjadi tiga berdasarkan fungsinya. Sirkulasi pertama adalah sirkulasi untuk fungsi pemilahan yang dibagi lagi menjadi jalur untuk pengunjung, pengunjung dengan kendaraan, dan mobil pengangkut sampah plastik. Jalur ketiga 
pengunjung ini dibedakan untuk menjaga keselamatan dan kenyamanan pengunjung. Sirkulasi kedua adalah sirkulasi untuk pengolahan sampah plastik. Sirkulasi ini dibuat dapat memutari fasilitas agar segala sisi pengolahan dapat diakses oleh kendaraan pengangkut atau kendaraan keselamatan darurat. Sirkulasi yang terakhir adalah sirkulasi rekreasi yang berfungsi untuk membuka wawasan masyarakat mengenai proses pengolahan sampah plastik serta kesadaran ekologis. Jalur ini dibuat interaktif agar dapat menarik perhatian pengunjung.Berikut adalah visualisasi dari penjelasan diatas.
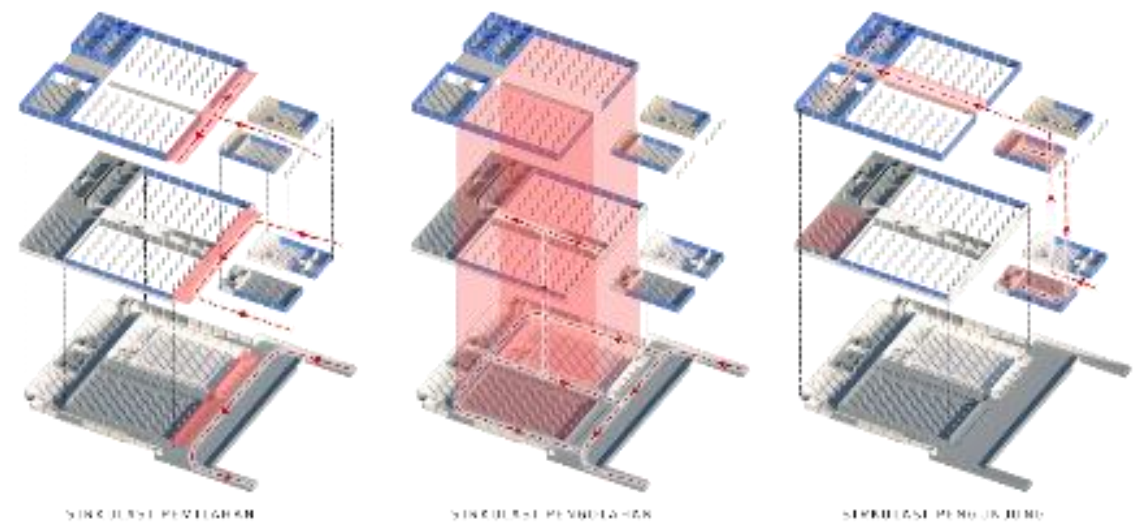

Gambar 4. Sirkulasi dalam Proyek

Sumber: Penulis, 2021

3. Penyempurnaan massa bangunan sesuai kebutuhan fungsional pendukuung bangunan Kebutuhan sistem pengumpul air hujan pada proyek direalisasikan dengan bentuk atap yang melengkung untuk mengaliri air hujan menuju titik-titik pengumpulan yang telah ditentukan. Kebutuhan peneduhan pada beberapa titik sirkulasi di luar bangunan direalisasikan dengan penutup atap terpisah berupa atap membran yang ditopang oleh tiang penopang. Tiang penopang ini dapat digunakan sekaligus untuk penangkal petir dan menciptakan suatu ciri khas simbolik dari bangunan.

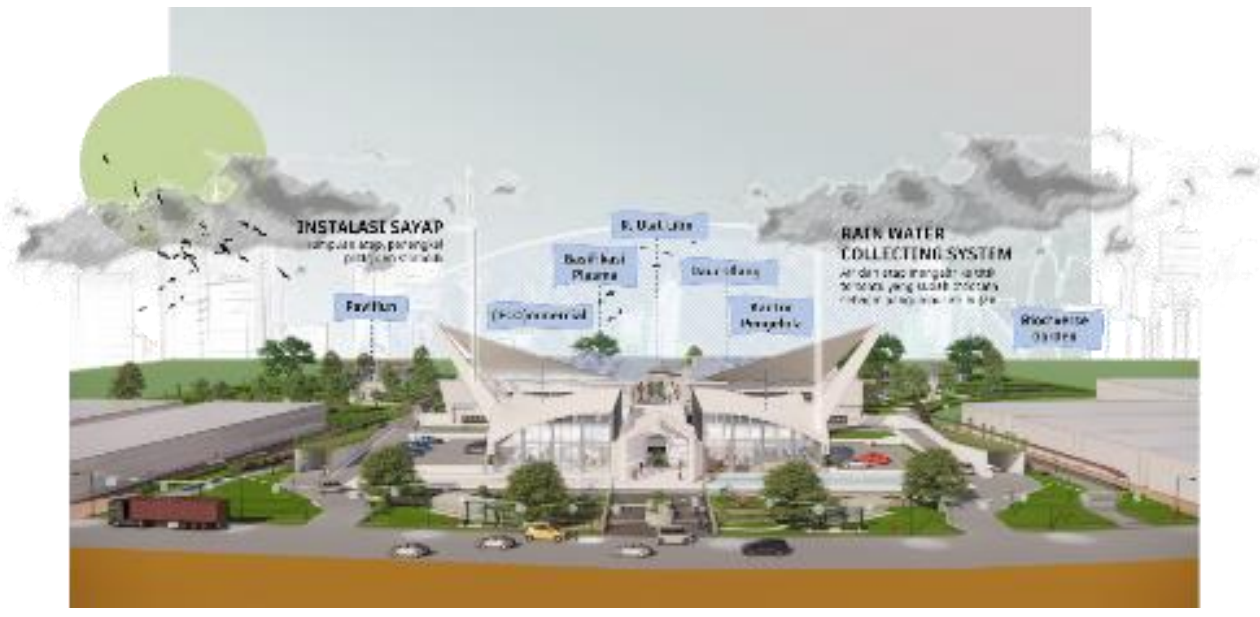

Gambar 5. Hasil Perancangan

Sumber: Penulis, 2021

\section{Penerapan Industri Ekologis pada Bangunan}

Sebagaimana menjadi tujuan pada awal perancangan, bangunan direncanakan untuk menjadi arsitektur industri ekologis yang tidak memberi dampak buruk pada lingkungan sekitar baik itu saat perencanaan, pembangunan, perawatan, hingga penghancuran. Langgam industri ekologis 
diterapkan pada material bangunan yang juga berpengaruh pada bentuk bangunan. Berikut adalah kriteria yang dicapai dan penerapannya pada bangunan yang juga mempengaruhi bentuk dan tampilan bangunan.

1. Sumber daya dan buangan bersih

Penggunaan sumber daya pertama yang berasal dari panel surya mengubah tampilan bangunan dari atas. Material atap menggunakan GFRP yang diselingi kaca dan panel surya untuk mencapai kebutuhan penutup atap, cahaya alami, dan pemasok energi.

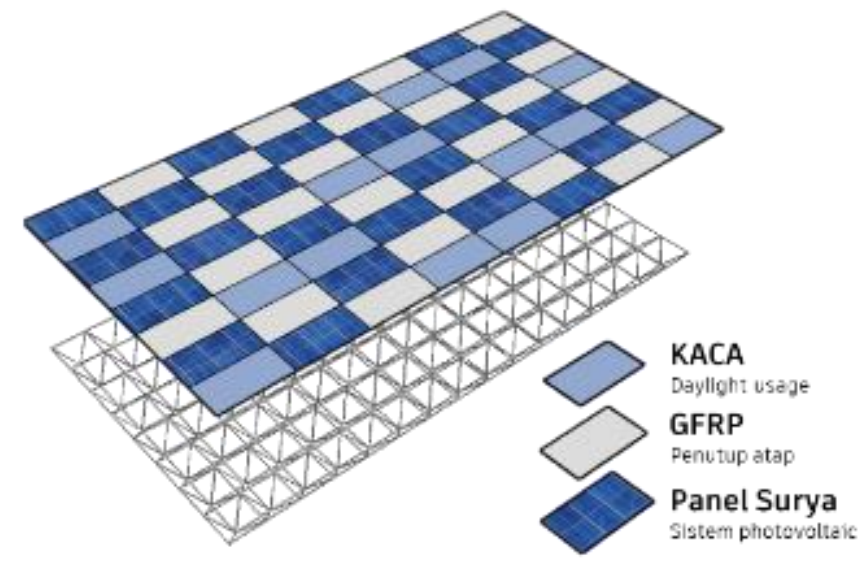

Gambar 6. Detail Material Atap

Sumber: Penulis, 2021

2. Penggunaan material yang dapat didaur ulang atau hasil daur ulang

Material yang digunakan pada bangunan berbahan dasar kaca, logam, dan plastik. Struktur menggunakan material baja dan dibiarkan terbuka untuk meminimalisir penggunaan material tambahan yang tidak perlu, sedangkan untuk partisi bangunan menggunakan material bata plastik daur ulang dan kaca. Penggunaan material-material ini sangat mempengaruhi tampilan akhir dari bangunan yang dirancang.

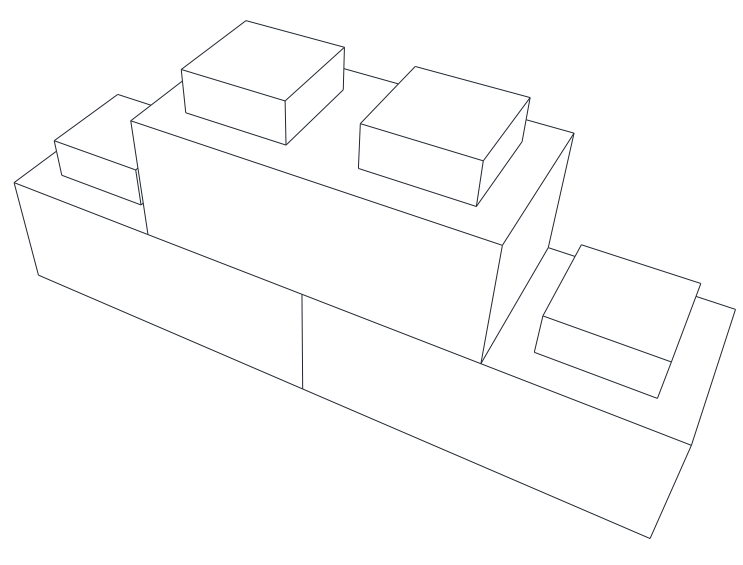

Gambar 7. Material Bata Plastik Daur Ulang

Sumber: Penulis, 2021

3. Terkoneksi dengan alam

Bangunan dibuat membaur dengan alam dan diterapkan dalam program ruang hidup ulat lilin dan sirkulasi pengunjung. Massa ruang hidup ulat lilin dibuat melingkar agar sesuai dengan cara hidup ulat lilin yang tinggal di sarang lebah pada pohon besar untuk berkembang. 


\section{KESIMPULAN DAN SARAN}

\section{Kesimpulan}

Pembentukan massa pada proyek Khanah Kufu dengan metode bentuk mengikuti fungsi berfokus pada kebutuhan ruang dan sirkulasi pada bangunan. Keputusan penggunaan metode ini menghasilkan bangunan industri yang efektif dan efisien dalam melaksanakan tujuannya untuk mewadahi fasilitas pengolahan sampah plastik. Struktur dan material pada bangunan ikut serta mempengaruhi bentuk dan tampilan bangunan.

Dari proyek ini didapati bahwa sangat penting untuk terlebih dahulu mengerti secara mendalam permasalahan dan tujuan proyek perancangan sebelum mulai merancang. Pengertian ini kemudian memberi gambaran besar tentang bagaimana proyek tersebut akan dibuat dan bagaimana caranya. Kemudian metode perancangan ditentukan agar proses perancangan tidak berbelok dari tujuan awal.

Metode pragmatis membantu untuk mengerti secara menyeluruh permasalahan yang akan diselesaikan dan solusi yang diterapkan merupakan solusi yang logis dan bersifat fungsional. Didukung dengan metode bentuk mengikuti fungsi maka hasil perancangan menjadi perancangan yang bersifat fungsional. Penambahan unsur-unsur yang ingin diutamakan pada perancangan dapat dilakukan pada awal perancangan sehingga proses perancangan berjalan sesuai dengan tujuan awal.

\section{Saran}

Setiap perancang disarankan untuk mengerti secara mendalam persoalan dasar dari proyek yang ingin dirancang, menentukan program ruang dan besarannya serta alur sirkulasi aktivitas, dan fokus utama lainnya sebelum menuju ke tahap perancangan dengan metode bentuk mengikuti fungsi.

\section{REFERENSI}

Conticelli, E. (2014). Eco-Industrial Parks and Sustainable Spatial Planning: A Possible Contradiction?. MDPI, 4(3), 331-349.

Hwang, Kun. (2020). Form Follows Function, Function Follows Form. The Journal of Craniofacial Surgery, 31(2), 10.1097

Lexy, M. (2011). Metodologi Penelitian Kualitatif. Bandung: PT Remaja Rosdakarya

Manvi, N. (2017). Impact Industrialization on the Building. International Journal of Engineering Research and Technology.

Sutanto, A. 2020. Peta Metode Desain. Jakarta

Styana, U. I. F. (2019). Karakterisasi Proses Gasifikasi Sampah Organik dengan Variasi Jenis Bahan. Jurnal Engine, 3(1), 2579-7433.

Sumartiningtyas, H. K. N. 2020. Indonesia Hasilkan 64 Juta Ton Sampah, Bisakah Kapasitas Pengelolaan Tercapai Tahun 2025?. Diakses 2 Maret 2021. https://www.kompas.com/sains/read/2020/ 12/18/070200023/indonesia-hasilkan-64juta-ton-sampah-bisakah-kapasitas-pengelolaan?page=all

sipsn.menlhk.go.id. (2020). Grafik Komposisi Sampah. Diakses pada 2 Februari 2021. https://sipsn.menlhk.go.id/sipsn/

www.usatoday.com. (2020, 6 Maret). These tiny, plastic-munching caterpillars can clean up our world but there's a catch. Diakses pada 8 Maret 2021. https://www.usatoday.com/story/news/ nation/2020/03/06/waxworms-caterpillarseat-plastic-pollution-but-could-also-hurt-bees/4952495002/ 
